\title{
REAL ECONOMIC DEVELOPMENT IN THE SOUTH: THE IMPLICATIONS OF REGIONAL COST OF LIVING DIFFERENCES
}

\author{
Gary M. Fournier and David W. Rasmussen*
}

\section{Introduction}

Two decades of rapid economic development in the South have greatly reduced the income differences that have long existed between this region and the rest of the country. The South has experienced dramatic improvements in a broad spectrum of economic indicators, including the number of jobs, wage rates, per capita income and poverty levels. ${ }^{1}$ In fact, some recent evidence indicates that the long standing North/South wage differential may have reversed itself, with real wages now higher in the South. ${ }^{2}$

When attempting to assess relative economic development among regions of the country, it is essential to recognize first that the costs of goods and services, and hence the purchasing power of income, vary substantially among localities. Just as one must correct for inflation when making income comparisons over time, income levels used to compare places should be adjusted for variations in the local costs of goods and services.

In this paper we present estimates of cost of living for the 48 contiguous states and use them to adjust relative measures of economic development for individual states and the four major regions. The task is easier said than done because the Bureau of Labor Statistics (BLS) data constructed for cost of living comparisons covers only a limited number of SMSAs. To overcome this problem, we show that within the BLS sample, variations in cost of living can be explained systematically with multivariate regression models using widelyavailable explanatory variables. As a result, we can incorporate least-squares predictors of cost of living for places outside the BLS sample to form statewide indexes, while maintaining modest prediction error.

The next section shows the impact of cost-of-

\footnotetext{
*Assistant Professor of Economics, Florida State University and Professor of Economics, Florida State University.
}

living adjustments on the per capita income measure of regional economic development. Because of the relatively low cost of living in the South, the level of economic development is often underestimated. A question of related interest is whether cost of living variations have a similar impact on the South's notoriously low level of transfer payments to poor families.

\section{Estimating Statewide Cost of Living Indices}

The Bureau of Labor Statistics has produced a family budget series designed to reflect the relative cost of living among 37 SMSAs. $^{3}$ There are inherent limitations to any attempt at measuring relative cost of living among localities for several reasons. Expenditures on some goods and services depend not only on relative prices but also on the availability of recreational resources, climate, the quality of public roads and transportation, and a host of other factors. Likewise, the composition of a typical family budget depends upon family income, with low income families purchasing a very different bundle of goods and services than a middle or high income family. The BLS series attempts to control for these factors, albeit crudely, by extensive surveys of family budgeting at each locality.

One particular limitation in the BLS data is the sample size, which comprises 37 cities in 1980 and 22 cities in 1970 . The consequence is that we cannot directly observe cost of living for most cities in the United States. There is good evidence, however, that the BLS data can be reliably employed for out-of-sample forecasting. Previous work has shown that within the BLS sample, cost of living varies systematically in reduced-form regressions which include proxies for urbanization, taxation and region (Cebula, 1980 and 1983; Haworth and Rasmussen, 1973). These studies reveal that the determinants of geographic variations in the cost of living are relatively uniform among localities within the United States, and that spatial variations can be estimated empirically with regression models 
derived from the theoretical literature in urban economics. One study (McMahon and Melton, 1978) actually constructed a cost of living index for states using this approach, although certain features of the model make it undesirable for us to simply replicate it. ${ }^{4}$

Our methodology is to construct a crosssection regression for cost of living, $Y$, solely for the purpose of obtaining predicted values of $Y$ for localities outside the BLS sample. This approach moderates two concerns which are sometimes raised in empirical work. First, since we are not concerned with interpreting the individual coefficients in the regression, it is unnecessary to develop a model containing a full structural system for the determination of $\mathrm{Y}$ and the explanatory variables, $\mathrm{X}$ (see e.g., Chow, 1983). Instead, we assume that the joint distribution of $\mathrm{Y}$ and $\mathrm{X}$ is multivariate normal, and that out-of-sample observations on $\mathrm{X}$ are drawn from the same distribution as those within the sample. This means, incidentally, that the coefficients cannot be interpreted in the usual way, i.e., they provide no information about the structural parameters. A more extensive discussion of the econometric properties of our estimation can be found in Fournier and Rasmussen (1986).

Second, with the present effort designed to maximize predictive power rather than test hypotheses about the determinants of variations in cost of living, our choice of a particular specification need not resolve differences in specifications used in reported studies. We select explanatory variables based on goodnessof-fit criteria, subject to the constraint that data be available for all SMSA and non-SMSA areas in the contiguous 48 states. To begin with, we took measures of components of the total cost of living, on the grounds that these components would tend to be highly correlated with Y. Housing costs and taxes are two components which are published for SMSAs. Housing costs, measured alternatively by median house value, HV, and contract rent, CR, are strongly affected by urban development, which in turn affects cost of living generally. Variations in tax liabilities are also known to contribute to differences in living costs among places. To capture the effect of taxes, we constructed two variables, the per capita state government revenues, STAX, and per capita local government revenues, LTAX. Finally, we include in our estimating equations a variable for population, POP, and three variables for the four census regions of the country, Northeast, N, North Central, NC, and South, S, to capture differences in the degree of urbanization and regional development. To allow the regional variables to interact with the housing cost variable in the equations, we incorporate slope dummy variables. For instance, to permit estimation of a different coefficient for housing costs for each region in the country, we include $\mathrm{N} \bullet \mathrm{HV}, \mathrm{NC} \cdot \mathrm{HV}$, and $\mathrm{S} \bullet \mathrm{HV}$, or alternatively, the set $\mathrm{N} \bullet \mathrm{CR}, \mathrm{NC} \bullet \mathrm{CR}$, and $\mathrm{S} \bullet \mathrm{CR}$. Complete observations on all variables are available for the entire United States.

To estimate the relationship between these variables and the intermediate and low income family budgets prepared by the BLS, observations were taken on census years 1970 and 1980, for which measures of population and housing costs are most accurate and detailed. Data were then pooled for the two years to increase the degrees of freedom in the sample. Although it is possible for structural changes to have occurred between these two years, standard F-tests indicate that parametric shifts were confined to the intercept alone. Hence a dummy variable for the year 1970 was included in the estimated equation.

The regression results are reported in Table 1 for both the low and intermediate family budgets. The models are identical except that contract rent is used to estimate the low family budget, reflecting the likely absence of homeownership, while median house value is employed in the equation for intermediate budget. In both regressions, variables are constructed to allow for interaction effects between region and housing costs. As shown in Table 1, the regressions are highly successful in terms of predictive power; the coefficient of determination adjusted for degress of freedom is above .98 in both regressions. Together with the root mean square error, RMSE, these goodness-offit measures suggest that prediction errors will be modest. Our initial specification tests, not reported here, indicate that the predictions on $Y$ were quite robust to alternative specifications of the explanatory variables, a result which is not surprising given the goodness-offit. ${ }^{\circ}$

Because achieving predictive power is the purpose of the regressions reported in Table 1 , it is not appropriate to place emphasis on the 
Table 1

Ordinary Least Squares Regressions on Cost of Living

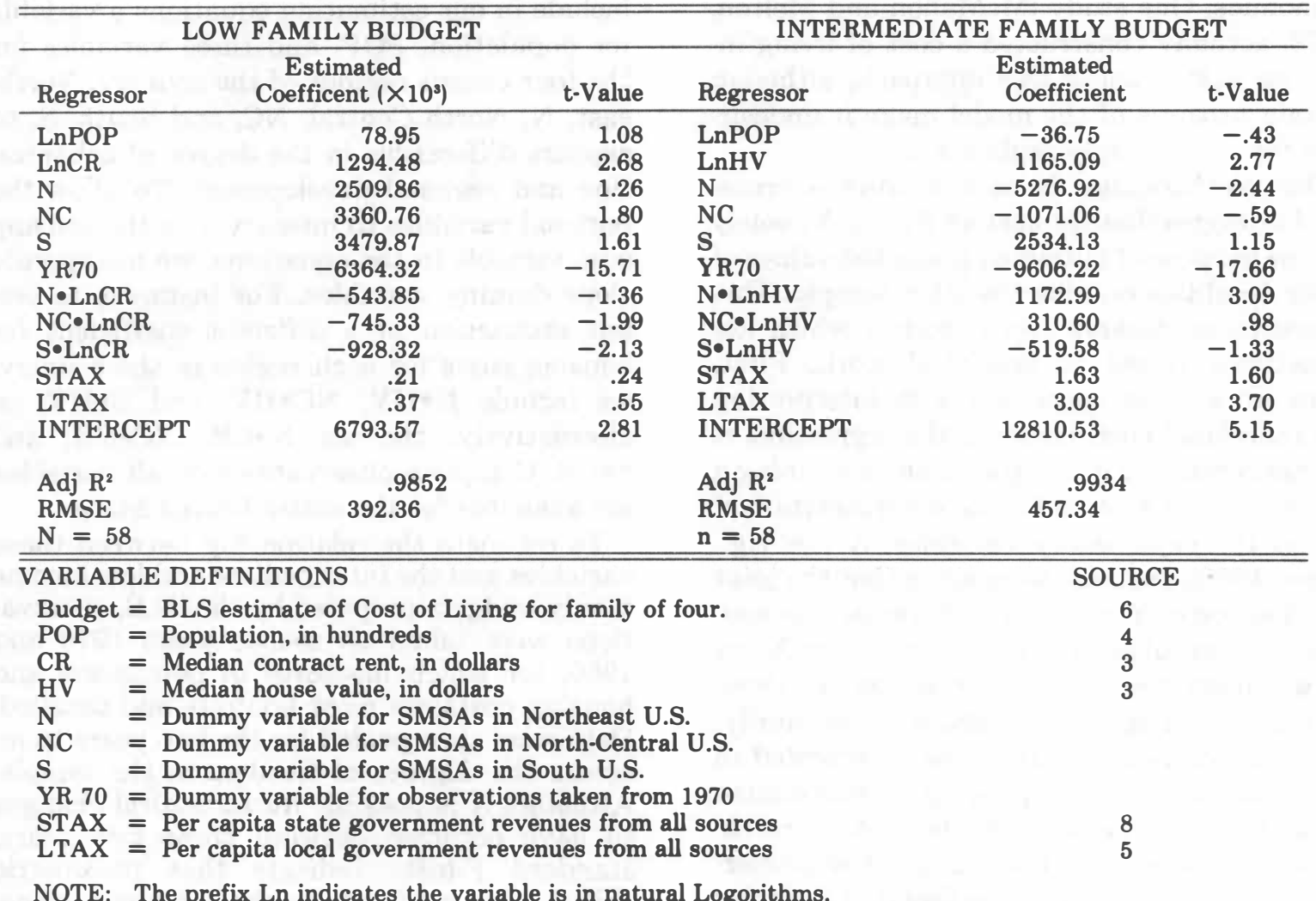

individual coefficients as though they were derived from an underlying theoretical structure. Nevertheless, a few words on the results are in order. As expected, the shift variable reflecting changes in cost of living from 1970 to 1980 is highly significant. The housing cost variable is significant at the .01 level in each regression. In the low family budget the interaction between contract rent and the South dummy is significant at the .05 level.while the North Central dummy and its interaction with contact rent is significant at the .10 level. In the intermediate budget regression, house value, local government revenues, and the North interaction with house value are significant at the .01 level. Thus, there is generally a high degree of explanatory power associated with the variables for housing costs, region, and their interaction. As we will see below, the joint effect of these variables is a relatively low cost of living in the South for both budgets. ${ }^{6}$

The regressions reported in Table 1 were used to estimate indices of relative cost of living for the 48 contiguous states. For every metropolitan area (SMSA) in the state, we computed the predicted values of cost of living from the least squares coefficients. ${ }^{7}$ In addition, separate estimates were obtained for the entire non-metropolitan portion of every state. ${ }^{8}$ Recognizing that in rural areas living costs are not affected by population, we dropped this variable out of the equation and used housing cost, region and taxes in the entire nonmetropolitan area of the state to predict cost of living. Finally, the statewide cost of living index, COL, is found by taking a weighted average of the SMSA and non-metropolitan area costs of living, where the weights are simply the fraction of the state's population in the area. ${ }^{9}, 10,11$

The relative costs of living for the low and intermediate budget are shown for each state in Table 2. The index is scaled so that the mean value is 100 . For the low budget the highest cost state is California, which is 10 percent higher than the average cost of living in the United States. The lowest cost state is Arkansas with an index of 91.306. Thus there is a range of approximately 19 percent between the highest and lowest cost state. For the in- 
Real Economic Development in the South:

The Implications of Regional Cost of Living Differences

TABLE 2

Low and Intermediate Cost of Living Estimates by State for 1980

\begin{tabular}{|c|c|c|c|c|}
\hline & \multicolumn{2}{|c|}{ Low Budget } & \multicolumn{2}{|c|}{ Intermediate Budget } \\
\hline State & Index & St. Error & Index & St. Error \\
\hline Alabama & 92.30 & 3.17 & 90.88 & 1.94 \\
\hline Arizona & 106.18 & 2.86 & 97.70 & 1.92 \\
\hline Arkansas & 91.30 & 3.93 & 89.86 & 2.50 \\
\hline California & 110.16 & 1.96 & 103.44 & 1.35 \\
\hline Colorado & 107.10 & 2.68 & 99.47 & 1.88 \\
\hline Connecticut & 103.75 & 2.27 & 110.88 & 2.00 \\
\hline Delaware & 102.29 & 3.91 & 105.20 & 2.70 \\
\hline Florida & 95.50 & 2.13 & 92.71 & 1.48 \\
\hline Georgia & 93.07 & 3.22 & 92.36 & 2.06 \\
\hline Idaho & 101.46 & 4.70 & 95.61 & 3.13 \\
\hline Illinois & 102.80 & 2.51 & 102.32 & 1.74 \\
\hline Indiana & 100.19 & 2.36 & 97.95 & 1.63 \\
\hline Iowa & 98.95 & 4.06 & 100.60 & 2.71 \\
\hline Kansas & 99.45 & 3.39 & 99.64 & 2.26 \\
\hline Kentucky & 91.91 & 3.87 & 91.08 & 2.37 \\
\hline Louisiana & 93.29 & 3.02 & 92.52 & 2.01 \\
\hline Maine & 99.94 & 4.21 & 102.00 & 2.82 \\
\hline Maryland & 105.08 & 2.69 & 109.23 & 1.94 \\
\hline Massachusetts & 104.32 & 2.34 & 108.75 & 1.67 \\
\hline Michigan & 102.52 & 2.25 & 101.03 & 1.60 \\
\hline Minnesota & 100.98 & 3.28 & 103.08 & 2.12 \\
\hline Mississippi & 90.72 & 4.44 & 90.89 & 2.80 \\
\hline Missouri & 99.18 & 2.96 & 97.38 & 1.88 \\
\hline Montana & 101.89 & 4.56 & 98.10 & 3.06 \\
\hline Nebraska & 99.44 & 3.87 & 101.34 & 2.54 \\
\hline Nevada & 108.77 & 3.08 & 100.53 & 2.02 \\
\hline New Hampshire & 101.42 & 4.26 & 104.81 & 2.85 \\
\hline New Jersey & 105.75 & 2.17 & 109.94 & 1.67 \\
\hline New Mexico & 102.51 & 4.01 & 95.51 & 2.68 \\
\hline New York & 106.36 & 2.74 & 113.51 & 1.75 \\
\hline North Carolina & 92.22 & 3.40 & 91.06 & 2.13 \\
\hline North Dakota & 99.13 & 3.97 & 100.86 & 2.62 \\
\hline Ohio & 101.04 & 2.05 & 99.59 & 1.40 \\
\hline Oklahoma & 93.05 & 3.25 & 91.60 & 2.06 \\
\hline Oregon & 105.94 & 2.93 & 99.30 & 1.99 \\
\hline Pennsylvania & 102.72 & 2.42 & 103.33 & 1.61 \\
\hline Rhode Island & 102.62 & 3.29 & 105.06 & 2.39 \\
\hline South Carolina & 92.33 & 3.23 & 90.77 & 2.02 \\
\hline South Dakota & 97.49 & 4.85 & 99.02 & 3.19 \\
\hline Tennessee & 93.17 & 2.91 & 91.24 & 1.92 \\
\hline Texas & 94.83 & 2.25 & 92.02 & 1.52 \\
\hline Utah & 104.85 & 2.92 & 96.37 & 2.11 \\
\hline Vermont & 99.60 & 4.49 & 104.92 & 3.10 \\
\hline Virginia & 94.33 & 2.59 & 92.96 & 1.91 \\
\hline Washington & 106.54 & 2.62 & 98.90 & 1.76 \\
\hline West Virginia & 91.67 & 4.06 & 91.26 & 2.67 \\
\hline Wisconsin & 100.79 & 2.81 & 102.01 & 1.90 \\
\hline Wyoming & 105.01 & 4.96 & 102.32 & 3.33 \\
\hline U.S. & 100.00 & & 100.00 & \\
\hline \multicolumn{5}{|l|}{ U.S. Average } \\
\hline Cost of Living & $\$ 13,483$ & & $\$ 22,595$ & \\
\hline
\end{tabular}

termediate budget the range is higher, from $\mathbf{8 9 . 8 6}$ for Arkansas to 113.51 for New York. Inspection of these data reveal that the South is the lowest cost region for both budget categories. The most expensive region for the low budget is the West, while the Northeast is the highest cost region for the intermediate budget category. This result might be explained by differences in the importance of certain items, such as housing costs, in the two budgets. On the whole, these indexes present an intuitively reasonable set of relationships among places. In what follows, we will use them to obtain real or constant purchasing 
power figures useful in assessing the level of economic development among the states and regions.

\section{Real Variations in Regional Economic Development}

Economic development is obviously a complicated and dynamic process that cannot be captured in a single number or index. When a snapshot of the level of economic development is required, the level of per capita income is most often used. However, given the very large differences in the cost of living, the nominal comparisons that are usually employed will obviously distort the actual variations in economic well being. These real and nominal per capita income comparisons are reported in this section.

Kuznets (1955) hypothesized that income inequality tended to fall with greater economic development as measured by the level of income. This hypothesis has been confirmed by an analysis of income inequality among states (Aigner and Heins, 1967; Al-Samarrie and Miller, 1967) and for SMSAs (Long, Haworth and Rasmusen, 1977; Nord, 1980; and Garofalo, 1979). The evidence suggests that in the past income equality was enhanced by rising manufacturing employment that accompanied economic development. Increased economic development could also result in greater solicitude for the poor, resulting in less inequality as a result of greater transfer payments. Failure to recognize the South's relatively low cost of living would mean that its level of economic development is often underestimated. It is also possible that the value of income transfers to the poor in the South are closer to the national average than commonly believed. We investigate this possibility by comparing nominal and real variations in the average monthly Aid to Families with Dependent Children (AFDC) payments among the states.

The results are shown in Table 3. Adjusting for cost of living differences raises per capita income in the South relative to the rest of the country. In nominal terms per capita income in the South is .82 of the West, .83 of the Northeast, and .88 of the North Central region. These comparisons in real terms are .91 (West), .99 (Northeast), and .96 (North Central). If the level of economic development is measured by per capita income, cost of living differences account for virtually all of the nominal differences between the South and Northeast, half of the differences between the South and West and about two-thirds of the differences between the South and North Central states.

Achieving near parity in the level of real per capita has not resulted in anything resembling equality between the South and other regions in terms of solicitude for the poor as measured by average monthly AFDC payments. Average real payments in the South are only .46 of the West, .50 of the Northeast, and .53 of the North Central region. It is interesting to note that these comparisons appear to refute the "supply side" argument that posits a causal relationship between rapid growth in the South and its relative neglect for the poor, where such neglect is supposed to provide work incentives essential for economic growth. The comparison here shows that the West has also reaped the advantages of rapid growth while exhibiting much higher average AFDC payments. In this regard the South is in clear contrast to the rest of the nation; while it has achieved more than 90 percent parity with the rest of the nation in terms of income, it chooses to commit about 50 percent fewer resources to average monthly AFDC payments.

The comparisons presented above are far from complete, so we will supplement them with two additional observations. First, AFDC payments per family would understate the degree of solicitude to the poor for states or regions with relatively large numbers of poor people, or for states/regions with a relatively high AFDC-recipient rate among the poor. An alternative measure might be the aggregate expenditures on AFDC per capita. Just as per capita income reflects ability to pay, per capita expenditure on welfare more closely reflects solicitude to the poor to the extent it can be expressed in terms of the overall commitment of resources. Table 4 shows how levels of expenditures compare by regions. Clearly, the real value of AFDC payments per capita is far lower in the South than in other regions. While per capita income is .99 of the Northeast, per capita payments for AFDC are only .36 of the level in the Northeast. Finally, we must be careful about interpreting AFDC payments per family as a measure of solicitude to the poor because there may be welfare programs other than AFDC, so that the AFDC figures 
Real Economic Development in the South:

The Implications of Regional Cost of Living Differences

TABLE 3

Nominal Vs. Real Income Indicators of State Economic Development 1980

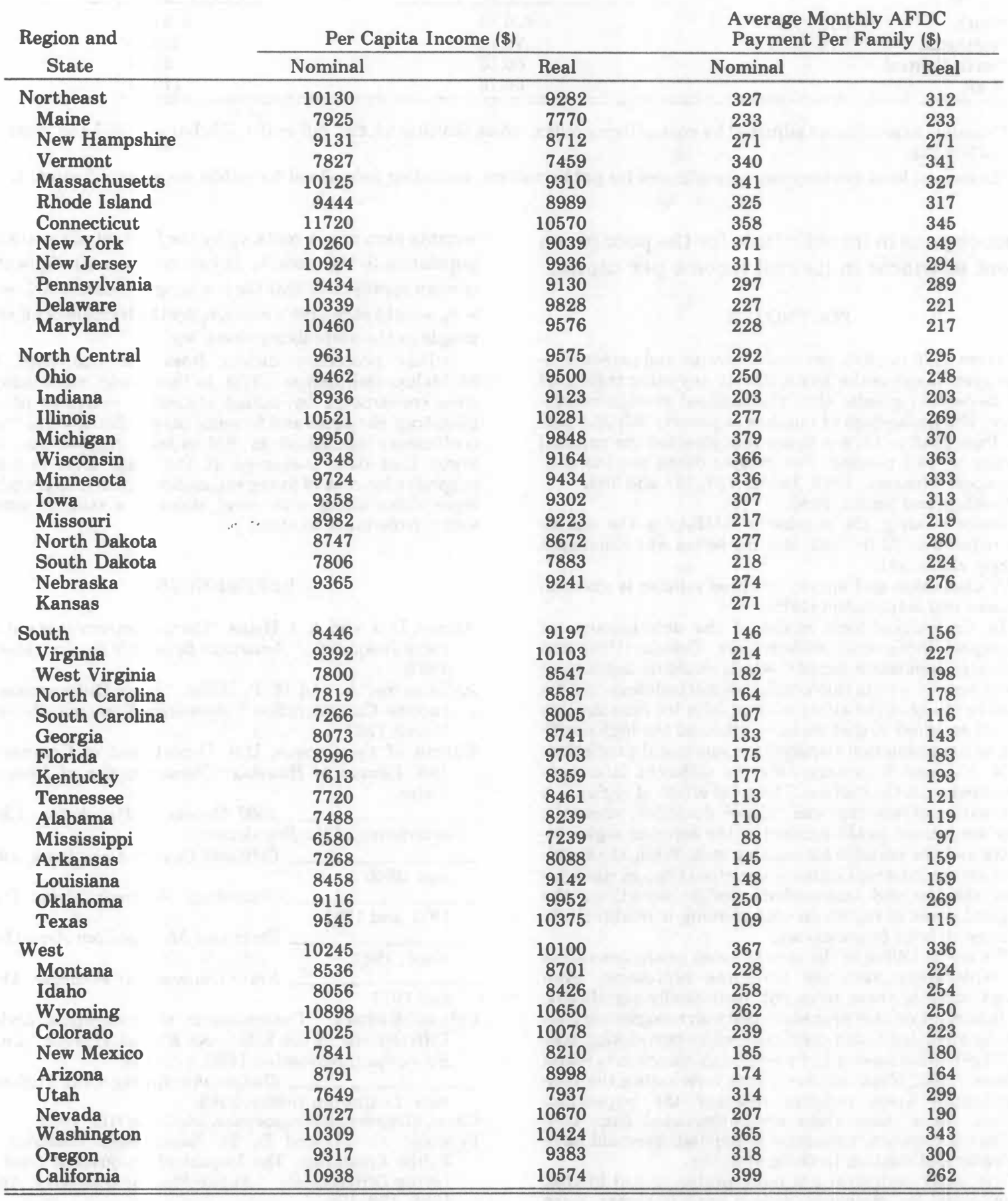

may convey a misleading impression of the impact rising incomes have on the status of the poor. If one broadens the definition of transfer payments to include all public welfare, Table 4 shows a similar, significant gap remaining between the South and other regions. Thus even allowing for differences in the mix of public assistance programs, the South lags far behind 
Table 4

A Comparison of Real Welfare Expenditures by Region, 1980

\begin{tabular}{|c|c|c|}
\hline Region & $\begin{array}{l}\text { Real }^{\text {a }} \text { AFDC Expenditures } \\
\text { Per Capita } \\
\end{array}$ & $\begin{array}{c}\text { Real }^{\mathrm{a}} \text { Public Welfare } \\
\text { Expenditures }^{\mathrm{b}} \text { Per Capita }\end{array}$ \\
\hline South & $\$ 26.86$ & $\$ 51.37$ \\
\hline Northeast & 75.11 & 125.26 \\
\hline North Central & 60.10 & 94.64 \\
\hline West & 66.76 & 113.64 \\
\hline
\end{tabular}

a Nominal expenditures adjusted by cost of living index, where South is 93.426 , NE is 104.759, NC is 99.867 and West is 108.122 .

bState and local government expenditures for public welfare, excluding federal aid for public assistance. Source: 7.

other regions in its solicitude for the poor given recent advances in its real income per capita.

\section{FOOTNOTES}

${ }^{1}$ From 1970 to 1980 , per capita income and personal income grew faster in the South than in any other region, 28 and 49 percent greater than the national average respectively. The percentage of families in poverty fell 26.5 percent from 1969 to 1979 , a figure that dwarfed the national average of 10.3 percent. For greater detail see the U.S. Statistical Abstract, 1984, Tables 750, 751 and 783 .

'Sahling and Smith, 1983.

${ }^{3}$ Unfortunately, the number of SMSAs in the sample was reduced to 22 in 1980 , and the series was eliminated entirely after 1981 .

A A discussion and survey of these studies is given in Fournier and Rasmussen (1986).

'In his reduced-form model of the determinants of geographic living cost differentials, Cebula (1980 and 1983) uses population density, which would no doubt have served equally well in this predictive methodology. An exhaustive study of the alternative proxies for urbanization was not required in that we have achieved the high coefficient of determination required for successful prediction.

${ }^{6} \mathrm{~N}, \mathrm{NC}$, and $\mathrm{S}$ capture only the different intercepts associated with the regions. The total effect of region is a combination of intercept and "slope" dummies, where the latter are formed as the product of the zero-one region indicator and the variable for housing cost. While the coefficients on the intercept dummy variables change signs between the low and intermediate budget equations, the marginal effect of region on cost-of-living is qualitatively the same in both formulations.

${ }^{7} \mathrm{We}$ are including in the cost of living predictions all of the explanatory variables from the regression, even though some of these were not statistically significant. Our judgment on this procedure rests on recognizing that deleting an insignificant coefficient risks introducing bias into OLS predictions on Y. Proof of unbiasedness is found in Chow, 1983. Note, however, that forecasting the nonmetropolitan areas requires deleting the population variable. Since these areas are constructed from noncontiguous counties, variations in population would have no meaningful relation to costs of living.

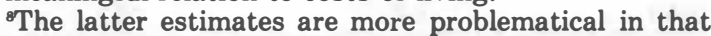
the potential for sample prediction error is higher, since the BLS sample does not contain areas of comparable size. We do not have the means to assess the severity of this problem with available data.

${ }^{9}$ Multi-state SMSAs are also apportioned among the states based on population weights.

${ }^{16}$ The intermediate budget index, ICOL $=\sum \lambda_{i} c_{i}$, weights each area's costs, $c_{i}$, by the fraction of the state's population living there, $\lambda_{j}$. In contrast, in our judgment it is more appropriate that the low budget index, LCOL $=\Sigma$ $w_{i} c_{i}$, weight each area's costs, $c_{i}$, by the fraction of all poor people in the state living there, $w_{i}$.

"This procedure differs from the one used by McMahon and Melton (1978). In that study, state indices were constructed by taking statewide measures of explanatory variables and forming the predicted value from coefficients estimated in SMSA-level regressions. We argue that data measured at the state level is inappropriate for cost of living estimation, since it aggregates large cities along with rural areas in a manner which varies from state to state.

\section{REFERENCES}

Aigner, D. J. and A. J. Heins. "On the Determinants of Income Inequality." American Economic Review, March 1967.

Al-Samarrie, A. and H. P. Miller. "State Differentials in Income Concentration." American Economic Review, March 1967.

Bureau of the Census, U.S. Department of Commerce, 1980 Census of Housing: Characteristics of Housing Units.

acteristics of the Population.
and 1982.
1971 and 1981.
Book, 1982.
and 1977.

Cebula, Richard. "Determinants of Geographic Living Differentials in the U.S.: : An Empirical Note." Land Economics, November 1980, 477-481. tials. Lexington Books, 1983.

Geographic Living Cost Differen-

Chow, Gregory. Econometrics, McGraw-Hill, 1983.

Fournier, G. M. and D. W. Rasmussen. "Salaries in Public Education: The Impact of Geographic Cost of Living Differentials. “ Public Finance Quarterly, April 1986, 179-198.

Garofalo, G. and M. Fogarty. "Urban Income Distribution and the Hierarchy-Equality Hypothesis." Review of Economics and Statistics, August 1979.

Haworth, Charles and David Rasmussen. "Determinants of Metropolitan Cost of Living Variations." Southern Economic Journal, October 1973, 183-92. 


\section{The Implications of Regional Cost of Living Differences}

Kuznets, Simon. "Economic Growth and Income Inequality." American Economic Review, March 1955.

Long, J., C. Haworth and D. Rasmussen. "Income Inequality and City Size." Review of Economics and Statistics, May 1977.

McMahon, W. W. and Carroll Melton. "Measuring Cost of Living Variations." Industrial Relations, October, 1978.

Nord, S. "Income Inequality and City Size: An Exam- ination of Alternative Hypotheses for Large and Small Cities." Review of Economics and Statistics, November 1980.

Sahling, Leonard and Sharon Smith. "Regional Wage Differentials: Has the South Risen Again?" Review of Economics and States, February 1983, 131-135.

Sherwood, Mark. "Family Budgets and Geographic Differences in Price Levels." Monthly Labor Review, April 1975, 8-15. 